\title{
Implementation of Cooperative Learning in Science: A Developmental-cum-Experimental Study
}

\author{
Sonam Mehta and A. K. Kulshrestha \\ Faculty of Education, Dayalbagh Educational Institute Deemed University, Agra 282005, India \\ Correspondence should be addressed to Sonam Mehta; sonamdei10@gmail.com
}

Received 30 January 2014; Revised 19 May 2014; Accepted 7 June 2014; Published 17 July 2014

Academic Editor: Eric Z. F. Liu

Copyright (C) 2014 S. Mehta and A. K. Kulshrestha. This is an open access article distributed under the Creative Commons Attribution License, which permits unrestricted use, distribution, and reproduction in any medium, provided the original work is properly cited.

\begin{abstract}
This research paper is designed to set forth ideas on how to implement cooperative learning and examine its effect on social and cooperative skills while imparting science education at the Secondary Level. The strategy used is Jigsaw Technique making heterogeneous groups based on intelligence and gender. Instructional material and observation schedule were constructed by researchers. The cooperative skills of the students were found improving during the experimental period, and they developed positive interdependence, face-to-face interaction skills, and feeling of individual accountability, as compared by Mann Whitney $U$ test. The students developed the feeling of working in a group in the classroom of science, and it also improved performance, as the discussion always leads to a considerable degree of clarity of concepts.
\end{abstract}

\section{Introduction}

In the modern era of science and technology, especially, in the realm of information technology, the approach to education has undergone significant changes. The philosophy of education has played a varied but pivotal role in shaping and designing curriculum. Pedagogy in this respect has also undergone major changes in accordance with the need of times. The teaching-learning process has become an issue of rational consideration and of critical query on various fronts, and there have been academic debates on the instructional material being provided to the students of various levels worldwide. The American Psychological Association in its report 2061 [1] validates the importance of innovative teaching methods in science by saying, "Calls for reforms in the ways we teach science at all levels, and in all disciplines are wide spread. The effectiveness of the changes being called for, employment of student-centered, active learning pedagogy, is now well supported by evidence. The relevant data have come from a number of different disciplines that include the learning sciences, cognitive psychology, and educational psychology. There is a growing body of research within specific scientific teaching communities that supports and validates the new approaches to teaching that have been adopted." The worldwide institutes of repute have conducted surveys, workshops, seminars, and research activities on pedagogy, teaching aids, infrastructure, and newly established theories in education (The Centre for Pedagogical Innovation (CPI), Brock University, Center for Teaching Excellence, Saint Anselm College). These theories, which give rise to methods and techniques of teaching, emphasize on the all-round development of students.

The students should have cooperative tasks in order to make student-student interaction effective for inventions are, actually, the result of the collaborative and cooperative work and not of an individual effort. As far as need for group work is concerned, science is slightly ahead compared to social sciences. A collaborative venture in the community of science, certainly, brings forth new dimensions to enrich and accomplish the classroom teaching of science.

The science today should enable the students to meet the demands and face the challenges ahead in work environment of daily life. Not only knowledge but also communication skills, leadership quality, critical thinking, and listening skills are required to achieve excellence in work. Describing the importance of new teaching methods in science involving 
group task in contrast to the old textbook recitation method, Association for Advancement of Science report [1, page 148] taking a "future" perspective states "The collaborative nature of scientific and technological work should be strongly reinforced by frequent group activity in the classroom. Scientists and engineers work mostly in groups and less often as isolated investigators. Similarly, students should gain experiences sharing responsibility for learning with each other. In the process of coming to understandings, students in a group must frequently inform each other about procedures and meanings, argue over findings, and assess how the task is progressing. In the context of team responsibility, feedback and communication become more realistic and are of a character very different from the usual individualistic textbookhomework-recitation approach (page 202)."

The education today should enable students to withstand against all oddities and challenges being faced by them at work place of routine encounters. The teaching method should not only serve the academic purpose but also develop social and cooperative skills recommended by educational agencies from time to time. To serve the purpose, among all the teaching methods being followed in the world, the cooperative learning has its own philosophic and psychosocial significance today. In the perspective of interaction, knowledge sharing, analysis, interpretation, and giving vent to subjective expression in group, cooperative learning is considered to be of great utility and wisdom. Following the introduction, the paper introduces cooperative learning and jigsaw strategy giving the contradictory findings and justification of using Jigsaw Technique. The next section deals with the design, sample, and experimental setup of the research followed by hypothesis, method, and development of instructional material and observation schedule. Further, the paper describes the period of implementation in classroom and the result it produces, leading to discussion followed by conclusion. The paper ends with implication in the classroom, limitations, and suggestion for further research.

\section{Cooperative Learning and Jigsaw Technique}

Cooperative learning is defined as a division for labour undertaken to solve a problem. For any given task, students divide the work and come together to present findings. Each student makes an individual contribution [2]. It is a teaching strategy in which small teams, each with students of different levels of ability, use a variety of learning activities to improve their understanding of a subject. Cooperative learning is different from collaborative learning. The basic difference is that collaboration is a philosophy of interaction and personal lifestyle where individuals are responsible for their actions, including learning, and respect the ability and contribution of their peers, whereas cooperation is a structure of interaction designed to facilitate the accomplishment of a specific end product or goal through people working together in groups [3]. Each member of a team is responsible not only for learning what is taught but also for helping teammates learn, thus creating an atmosphere of collective achievement. Zakaria and Iksan [4] believed that cooperative learning is grounded in the belief that learning is most effective when students are actively involved in sharing ideas and working cooperatively to complete academic tasks. Cooperative learning has also been implemented in lectures, but results are contradictory [5]. While Vreven and McFadden [6] found that students did not benefit from cooperative learning activities in lectures, students in a study by Cavanagh [7] greatly valued opportunities for engaging in lectures by means of cooperative learning activities. Through interaction students learn to interrogate issues, share ideas, clarify differences, and construct new understandings $[8,9]$. Furthermore, Toumasis [10] studied the effect cooperative learning had on 8th-10th graders' ability to read and understand mathematical textbooks. He determined that working cooperatively helped students "... form new friendships and learn to appreciate differences in ability, differences in personal characteristics and differences in opinion" (page 669). To seek the answer in a contradictory situation validating the importance of cooperative learning in Indian perspective, this research paper sets forth ideas on how to implement cooperative learning and examine its effect on social and cooperative skills while imparting science education at the Secondary Level.

Cooperative learning makes the use of varied techniques which are learning together and alone, constructive controversy group investigation, jigsaw procedure, student teams achievement divisions (STAD), complex instruction, team accelerated instruction (TAI), cooperative learning structures, and cooperative integrated reading and composition. Any of the techniques could have been used, but in the present study the technique used is Jigsaw Technique.

The justification of using Jigsaw Technique is the need of research in science; the adequate understanding of any phenomenon requires proper research by the students. Jigsaw strategy is the simulated setting of the scientists of scientific community. As the scientists do their research and discuss the results with their colleagues, which leads to new discoveries and inventions, in the same way the students do their assigned piece of work and discuss their knowledge with the group. In this study, groups with five students are set up. Concerning member selection, cooperative learning proponents suggest it is better that instructors assign students to groups $[11,12]$, because random grouping or self-selection by students is likely to exclude or negatively affect minority students [13, 14]. Each group is heterogeneous based on intelligence and gender, and the groups among themselves are homogenous. The effectiveness of the cooperative learning is checked by measuring social and cooperative skills of the students as a group. The principal goals of the study are as follows:

(1) to develop and implement instructional material for applying cooperative learning approach in ninth grade;

(2) to study the effect of cooperative learning technique on the social and cooperative skills of students.

\section{Experimental Materials and Methods}

3.1. Design and Sample. The research design used in the study is "one group, pretest and posttest" in which we observed the cooperative skills of the students before the implementation 
of the treatment we are providing them with (teaching by cooperative learning method), during the treatment, and then after the treatment. As sampling was purposive, the difference between the cooperative skills of the groups was calculated by Mann Whitney $U$ test. The experimental period was 10 days.

To know the effect of cooperative learning technique on the social and cooperative skills of students, a sample of the ninth class central board of secondary education (CBSE) was selected by purposive sampling. 40 students were selected which include both boys and girls in ratio 1:1 and students with average and high intelligence. The average age of the students was 14.5 years and the groups were heterogeneous in terms of intelligence and gender. 40 students had 8 home groups and at times 5 expert groups. To evaluate the effect on social and cooperative skills, the observation schedule developed by the researcher was employed. The teacher observed the group and acted as a facilitator to resolve the conflict in class within or among the groups.

3.2. Hypotheses. The hypotheses made for the study are as follows.

(1) There is no significant difference in the social and cooperative skills of the students before and during the implementation of cooperative learning based instructional material.

(2) There is no significant difference in the social and cooperative skills of the students before and after the implementation of cooperative learning based instructional material.

3.3. Method. Fulfillment of the above objectives and testing the hypotheses require the use of developmental method involving experimental setup in the classroom and quantitative statistics. The design of the instructional material is in accordance with the format used [15]. The development of instructional material was validated by the pilot study and opinion of 12 experts. The developed instructional material was used to teach the subjects for ten sessions in an experimental group. The development of instructional material was followed by checking its effect on the cooperative and social skills of the students. Since the researcher could not find an evaluation tool which would serve the purpose, a selfconstructed tool was employed on the students, that is, an observation schedule for evaluation of cooperative skills of students. The study is done in three steps: planning, implementing, and observing the skills. Planning phase includes the development and try-out of instructional material in pilot study. The science in ninth standard class has three parts: physics, chemistry, and biology. The researcher selected the field of biology as it is an area of more of students' practical life situation and the problems faced by them almost every day. With the consideration of the application of cooperative approach in the field of science, the topics selected include health and factors affecting it, disease and its various causes, how to become disease free, viral and bacterial infections, organ specific and tissue specific infections, and classification of the diversified living beings.

\section{Development of Instructional Material and Observation Schedule}

The development of the instruction material in accordance with the cooperative learning approach of teaching involves the critical analysis of the five elements of the cooperative learning, that is, positive interdependence, individual accountability, face-to-face interaction, small group processing, and social skills. Positive interdependence means that group members should perceive that the collective effort of the group is essential for the individual learners to achieve their goals [16]. Individual accountability means that, in order to prevent social loafing, the students should be assessed by their individual learning outcomes. Each group member is held accountable for his or her work. Individual accountability helps to avoid members from "hitchhiking" on other group members' accomplishments. Thus, while working within a group, the student might still pursue individual goals and be assessed as an individual. Awarding individual grades to students does not conflict with cooperative learning as it enhances individual accountability [5]. Promoting success of group members by praising, encouraging, supporting, or assisting each other is possible in face-to-face interaction in the best possible way. Cooperative learning groups set the stage for students to learn social skills. These skills help to build stronger cooperation among group members. Leadership, decision making, trust-building, and communication are different skills that are supposed to develop in cooperative learning setting. And the assessment of how groups are functioning to achieve their goals is determined by how effective group processing is. By reviewing group behaviour, the students and teacher get a chance to discuss needs or problems with the group. Groups do get a chance to express feelings about beneficial and unhelpful aspects to correct unwanted behavior and celebrate success.

Other key elements that are critical to the effective implementation of CL include promoting each other's learning, accepting responsibility for contributing to the group's efforts or task, demonstrating the interpersonal and small group skills needed to resolve conflicts, and monitoring and reviewing group's progress [17]. Moreover, students in structured groups are more task focused, provide more detailed explanations to each other to assist each other's understanding, use language that is more cognitively challenging, and attain higher learning outcomes [18-20].

Keeping in view all of these elements, the instructional material, that is, the lesson plans, was prepared adapting the lesson plan format given by [15]. The prepared instructional material was sent to 12 experts in the field of education, that is, six experts of teaching science, four school teachers of science, and two language experts, and they found it to be apt with regard to the knowledge and cognitive level of students of class ninth. Afterwards the material was applied on a small group (pilot study of the instructional material) and two modifications were done after the pilot study.

Based on the five elements of cooperative learning and their relation with the different aspects of the personality of students, the skills are decided to be included in the form of sixteen items of the tool. The elements are identified in the 
TABLE 1: Observation schedule (reliability: 0.85).

\begin{tabular}{|c|c|c|c|}
\hline \multirow{2}{*}{ S. No. } & \multirow{2}{*}{ Elements of cooperative learning } & \multicolumn{2}{|c|}{ Number of items included } \\
\hline & & First draft (16 items) & Final draft (14 items) \\
\hline 1 & Positive independence & 4 & 3 \\
\hline 2 & Individual accountability & 4 & 3 \\
\hline 3 & Group processing & 4 & 4 \\
\hline 4 & Face-to-face interaction & Setup of the class & Setup of the class \\
\hline 5 & Social skills & 4 & 4 \\
\hline
\end{tabular}

form of skills included. The skills included are affected by the cooperative learning method of teaching directly or indirectly validated by the opinion of the experts (face validity). The items are based on listening skills, power of expression of ideas, helping the members of the groups, initiative quality, relevance of ideas, and participation in the group.

As per the suggestions extended by the experts, two items were removed and two were modified linguistically and the final draft of the observation schedule with fourteen items was prepared and all of them were positive items. The schedule is a group evaluation form. They were checked on a five-point scale which included the assessment of every item in either of the following options: never, rarely, sometimes, usually, and always. The test retest reliability of the tool was found to be 0.85 (Table 1). The face validity and content validity were analysed by the content experts, and they found this tool to be valid. We assigned numerals to the responses, because all the items were positive, so 1 was assigned to never and 2, 3, 4, and 5 were assigned to rarely, sometimes, usually, and always, respectively. The coding of the items can be understood by taking the example of an item. The first item in the schedule is "Listen to each other." If all the students in a group listen to each other all the time during a session without arguing irrelevantly (they can have constructive discussion), the group was given the rating "always" for that session. This gave the raw data for statistical calculations.

\section{Implementation and Experimental Period}

The developed instructional material with all the modifications was employed in the classroom by making group of five students. The roles which are usually described in any other strategy were omitted here as the jigsaw strategy has all the students acting as the expert of the subtopic provided to them. Every topic was divided into five subtopics which makes 5 experts in each group. They were provided with the background of the topic and asked to discuss the topic within their group. They discussed the topic, shared the views, and came up with enhanced knowledge.

The cooperative skills of the students were observed in formal classroom setting four times during the ten-day period with the gap of two days between two consequent observations. The skills were observable as the fourteen items had the skills of listening, initiating the discussion, leading, and participating. All these skills were directly observable and were marked in the observation schedule. The observation of the first day was compared with that of the fourth day to see if there was any difference during that period. The Mann
TABLE 2: Descriptive statistics of the group in the observation schedule.

\begin{tabular}{lcc}
\hline Days & Mean & SD \\
\hline 1 & 2.89 & 2.93 \\
4 & 3.32 & 3.31 \\
7 & 3.65 & 3.66 \\
10 & 4.79 & 4.71 \\
\hline
\end{tabular}

Whitney $U$ test was employed to see the significant difference between the two if it exists. The same procedure was done between day 1 and day 7 and in case of day 1 and day 10 . This gave the cooperative skills of the students during the entire experimental phase. The mean and standard deviation of the observation of four days were given in Table 2. The observation schedule was employed on the very first day to know where the students actually stood, and then the skills were observed on the 4 th, 7 th, and 10th days. This depicted the effect of cooperative learning method on the skills of the students gradually.

\section{Results}

The result of the experiment shows a remarkable increase in the social and cooperative skills of the students over the period of ten days. The findings with respect to the 1st, 4 th, 7 th, and 10th days are given in the following points.

(1) Findings with regard to the cooperative skills of the students on the first day, that is, before the implementation of the cooperative learning based instructional material, depicted the mean score to be 2.89 and standard deviation (S.D.) as 2.93. This descriptive statistics gave the idea of the skills in students by default and homogeneity of the group. The mean and S.D. of the fourth day were 3.32 and 3.31, respectively. It was the score after the implementation of the instructional material. The mean scores of the first and fourth days were compared by employing Mann Whitney $U$ test and this resulted in significant difference between the cooperative skills of the students observed on day 1 and day 4 at 0.05 level of significance, indicating that the scores are improved.

(2) The mean and S.D. of the seventh day were 3.65 and 3.66 and the difference between day 1 and day 7 was found to be significant at 0.01 level of significance. 
TABLE 3: Difference between the scores of the first and the subsequent observations.

\begin{tabular}{lccc}
\hline Days & Sample size & $\begin{array}{c}\text { Statistical technique } \\
\text { Summation of ranks } \\
\left(\sum R\right)\end{array}$ & $U^{\text {obt }}{ }^{*}$ \\
\hline Day 1 & 40 & 149 & $\mathbf{4 4}^{*}$ \\
Day 4 & 40 & 257 & $\mathbf{1 7}^{* *}$ \\
\hline Day 1 & 40 & 122 & \\
Day 7 & 40 & 284 & $\mathbf{4}^{* *}$ \\
\hline Day 1 & 40 & 109 & \\
Day 10 & 40 & 297 & \\
\hline Note. ${ }^{*} p<0.05,{ }^{* *} p<0.01$. & &
\end{tabular}

(3) The mean and S.D. of the tenth day were 4.79 and 4.71 , respectively, and the difference between them was found to be significant at 0.01 level of significance. The lesser the value of $U$, the more significant the difference between the two values; and in Table 3, the values are given which shows the maximum difference between day 1 and day 10 showing a very significant improvement in cooperative and social skills of students during the period of ten days.

\section{Discussions}

The experimental phase can be marked as increasing intergroup and intragroup dialogue and interaction among students. From a constructivist perspective of learning, dialogue and argument are valuable learning opportunities [21, 22]; from this point of view, experiment was successful. Furthermore, with reference to first objective, the researcher developed the lesson plans in science including the topics of biology, physics, and chemistry and the lesson plans were implemented in the classroom which was problematic in the beginning as the students were much of passive listeners in the lecture method and took a day to adjust to this new method. Some students were shy to speak up on the first day but spoke from the $3 \mathrm{rd}$ and 4 th days.

Objective two required the information about the social and cooperative skills of the students on the first day and last day to see whether or not the skills are improving gradually, which was fulfilled by the positive results of the experiment. Students were enthusiastic regarding the cooperative learning method of teaching. In the beginning, students were hesitant to speak up in front of the whole class which decreased with time and they became confident. Not all the students are willing to participate in the group; some like to listen and put forward their view point only when asked. It states that the students developed their cooperative skills by using cooperative learning method in teaching and by letting the students decide when to learn and when to stop and when to move further. The 1st hypothesis of the study was rejected in the light of the results obtained by applying the statistics and analyzing the data of first-second and first-third observations as given in Table 3. In the same way, hypothesis 2 was also rejected. Social skills and the group processing were improved by teaching with cooperative learning method.
The students developed the feeling of working in a group in science classroom and it also improved their performance as the discussion leads to considerable clarity of concepts.

The cooperative learning approach to teaching increases not only the understanding of students but also the social and cooperative skills they exhibit. The study states that cooperative learning approach increases the social and cooperative skills of the students. Baghcheghi et al. [23] concluded that cooperative learning is an effective method for improved and increased communication skills of nursing students especially in interactive skills and Wang [24], in his research, concluded that students got a lot of experiences; students were more motivated to work hard which created a positive atmosphere. Siegel [25] concluded that because of its potential to increase student achievement and social skills development, cooperative learning has been advocated for school reform. To the existing facts, the present research adds an important finding that the social skills of the students also can be increased by cooperative learning method, which is revolutionary as many students lack social skills in the class and when they go out in job, it becomes their weakness.

\section{Conclusion}

The cooperative learning theory which plays an important role in the field of education recently aroused the interest of the experts in the field of science teaching in terms of designing a curriculum which enables the students to learn through cooperative effort, problem solving, and decision making. In a cooperative classroom, the teacher assumes the role of facilitator and guide. Teacher becomes the manager and not the controller of the class. Students take the responsibility of their own learning. They ask questions, state problems, design activities, and discuss their results with others. Students are more positive about each other when they learn cooperatively than when they learn alone, competitively, or individualistically - regardless of differences in ability, ethnic background, or being handicapped or not. This promotes the success of all the students. Learning is most effective when the learner is active and the process of learning is interesting for him/her. While there are limitations on when and where you may use competitive and individualistic learning, you may structure any learning task in any subject area with any curriculum by cooperative learning approach. The present study added one more reason to use cooperative learning method in the already existing numerous known and proved reasons.

\section{Implication in Classroom}

In pursuing a means to develop academic excellence in students of various levels in schools, cooperative learning has been proved to be effective [26]. In addition, cooperative learning, as mentioned earlier, is an excellent tool to develop new understanding about various concepts. If the relationship found in the present study stands true in further investigation, our understanding of cooperative learning and development of social skills of students can be improved further. For example, we will not label the students as good or bad 
or as low achiever or high achiever because they would be part of the team and not just an entity struggling to get the result alone. This insight would help the instructors improve the effectiveness of the instruction because they know that it is not just the classroom learning, but in fact the skill development of students. Similar interventions will require further investigation in future projects once this relationship is fully validated and explored.

\section{Limitations and Suggestions for Future Research}

As with all experimental studies, this study also has some limitations that will need to be addressed in future studies. In addition to increasing the sample size to confirm the result of this study, we also need to address the observation technique used in this study, which is by a single person. Further studies can be done by having objective observation involving 3 or 4 observers and the results would be even more valid that way. We also need to determine whether we can observe the skills in any other cooperative learning setting. The field of cooperative learning research can be explored more by carrying out research in other subjects like history, civics, English, mathematics, environmental science, social science, economics, and so forth. Cooperative learning method can be applied to study and compare its effect on the students of different culture. Further, the research can be carried out to study the effect of cooperative learning approach on the students of higher grade as well, as the students of higher grade are expected to be intellectually developed. This may be a question to be answered whether those students who have difficulty in learning and following the lecture given by the professors can benefit from this approach of teaching and an important study can be conducted on the achievement of slow learners and the impact of cooperative learning based instructional material on their learning habit and psychological traits.

\section{Appendix}

\section{Final Draft of Lesson Plan for Teaching Based on Cooperative Learning Method}

(Format by Johnson et al. [15])

\begin{tabular}{|c|c|}
\hline \multicolumn{2}{|l|}{ School: - - } \\
\hline Period: - - & Duration: - - \\
\hline Subject Area: - - & Date: -— \\
\hline Lesson: - - & Class: - - \\
\hline Numbers of Students: _- - & Number of Groups: - - \\
\hline
\end{tabular}

Objectives: - -

(i) Academic: - -

(ii) Social Skills: _-

Cooperative Strategy: Jigsaw Area of Expertise: - -

(i) Academic Task - - (ii) Criterion for Success - -

(i) Positive Interdependence - -

(ii) Individual Accountability - -

(iii) Expected Behaviour - -

Monitoring. Teacher would monitor and organize the whole class; intergroup and intragroup interactions would be organized in an effective way. It would be seen whether the groups are working as a team or they are just putting forward their views without listening to others. Teacher would resolve the conflict (if any) within a group or between two groups.

Behaviour Observed. The behavior of the students would be observed by observation schedule, a tool made by teacher.

Assessment of Learning:

(i) Small Group Processing - -

(ii) Goal Setting - -

(iii) Whole Class Processing - -

Task steps and procedures (Structuring the task)

Positive Interdependence: - -

Individual Accountability: Individual and Group assessment

End by: - -

Note

Small Group Processing. The interaction and discussions among the members of the same group.

Whole Class Processing. The interaction among the experts of every group on the same subtopic.

Positive Interdependence and Individual Accountability. Elements of cooperative learning in the group.

Jigsaw Technique of Cooperative Learning. Groups with five students are set up. Each group member is assigned some unique material to learn and then to teach his group members. To help in the learning students across the class working on the same subsection get together to decide what is important and how to teach it [21]. After practice in these "expert" groups the original groups reform and students teach each other. Tests or assessment follows.

\section{Conflict of Interests}

The authors declare that there is no conflict of interests regarding the publication of this paper. 


\section{References}

[1] American Association for the Advancement of Science, Science for All Americans: Project 2061, Oxford University Press, 1989.

[2] D. W. Johnson and R. Johnson, "Positive interdependence: key to effective cooperation," in Interaction in Cooperative Groups: The Theoretical Anatomy of Group Learning, R. Hertz-Lazarowitz and N. Miller, Eds., Cambridge University Press, New York, NY, USA, 1992.

[3] T. Panitz, "Collaborative versus cooperative learning: a comparison of the two concepts which will help us understand the underlying nature of interactive learning," Cooperative Learning and College Teaching, vol. 8, no. 2, pp. 5-7, 1997.

[4] E. Zakaria and Z. Iksan, "Promoting cooperative learning in science and mathematics education: a Malaysian perspective," Eurasia Journal of Mathematics, Science and Technology Education, vol. 3, no. 1, pp. 35-39, 2007.

[5] K. J. Hermann, "The impact of cooperative learning on student engagement: results from an intervention," Active Learning in Higher Education, vol. 14, no. 3, pp. 175-187, 2013.

[6] D. Vreven and S. McFadden, "An empirical assessment of cooperative groups in large, time-compressed, introductory courses," Innovative Higher Education, vol. 32, no. 2, pp. 85-92, 2007.

[7] M. Cavanagh, "Students' experiences of active engagement through cooperative learning activities in lectures," Active Learning in Higher Education, vol. 12, pp. 23-33, 2011.

[8] N. Webb and A. Mastergeorge, "Promoting effective helping behavior in peer-directed groups," International Journal of Educational Research, vol. 39, no. 1-2, pp. 73-97, 2003.

[9] R. Wegerif, N. Mercer, and L. Dawes, "From social interaction to individual reasoning: An empirical investigation of a possible sociocultural model of cognitive development," Learning and Instruction, vol. 9, no. 6, pp. 493-516, 1999.

[10] C. Toumasis, "Cooperative study teams in mathematics classrooms," International Journal of Mathematical Education in Science and Technology, vol. 35, no. 5, pp. 669-679, 2004.

[11] R. M. Felder, "Cooperative learning in the sequence of engineering courses: a success story," Cooperative Learning and College Teaching Newsletter, vol. 5, no. 2, pp. 10-13, 1995.

[12] S. Lighfner, M. J. Bober, and C. Willi, "Team-based activities to promote engaged learning," College Teaching, vol. 55, no. 1, pp. 5-18, 2007.

[13] S. V. Rosser, "Group work in science, engineering, and mathematics: consequences of ignoring gender and race," College Teaching, vol. 46, no. 3, pp. 82-88, 1998.

[14] P. J. Hinds, K. M. Carley, D. Krackhardt, and D. Wholey, "Choosing work group members: balancing similarity, competence, and familiarity," Organization Behavior and Human Decision Processes, vol. 81, no. 2, pp. 226-251, 2000.

[15] D. W. Johnson, R. Johnson, and E. Holubec, Cooperation in the Classroom, Interaction Book Company, Edina, Minn, USA, 8th edition, 2008.

[16] D. W. Johnson and R. T. Johnson, "An educational psychology success story: social interdependence theory and cooperative learning," Educational Researcher, vol. 38, no. 5, pp. 365-379, 2009.

[17] D. W. Johnson and R. Johnson, "Controversy and peace education," Journal of Research in Education, vol. 13, no. 1, pp. 71-91, 2003.
[18] R. M. Gillies, "The behaviors, interactions, and perceptions of junior high school students during small-group learning," Journal of Educational Psychology, vol. 95, no. 1, pp. 137-147, 2003.

[19] R. M. Gillies, "The effects of communication training on teachers'and students'verbal behaviours during cooperative learning," International Journal of Educational Research, vol. 41, no. 3, pp. 257-279, 2004.

[20] N. M. Webb, M. L. Franke, T. De et al., "Explain to your partner: teachers' instructional practices and students' dialogue in small groups," Cambridge Journal of Education, vol. 39, no. 1, pp. 4970, 2009.

[21] J. Biggs and C. Tang, Teaching for Quality Learning at University: What the Student Does, The Society for Research into Higher Education, Open University Press, Maidenhead, UK, 4th edition, 2011.

[22] A. Pritchard and J. Woollard, Psychology for the Classroom: Constructivism and Social Learning, Routledge, New York, NY, USA, 2010.

[23] N. Baghcheghi, H. R. Koohestani, and K. Rezaei, "A comparison of the cooperative learning and traditional learning methods in theory classes on nursing students'communication skill with patients at clinical settings," Nurse Education Today, vol. 31, no. 8, pp. 877-882, 2011.

[24] P. Wang, "Applying Slavin's cooperative learning technique to EFL conversation class," The Journal of Human Resource and Adult Learning, vol. 5, no. 1, pp. 112-120, 2009.

[25] C. Siegel, "Implementing a research-based model of cooperative learning," Journal of Educational Research, vol. 98, no. 6, pp. 339-349, 2005.

[26] R. Stevens and R. Slavin, “The Cooperative elementary school: effects on Students achievement, attitudes and social relation," The American Educational Research Journal, vol. 32, pp. 321-351, 1995. 

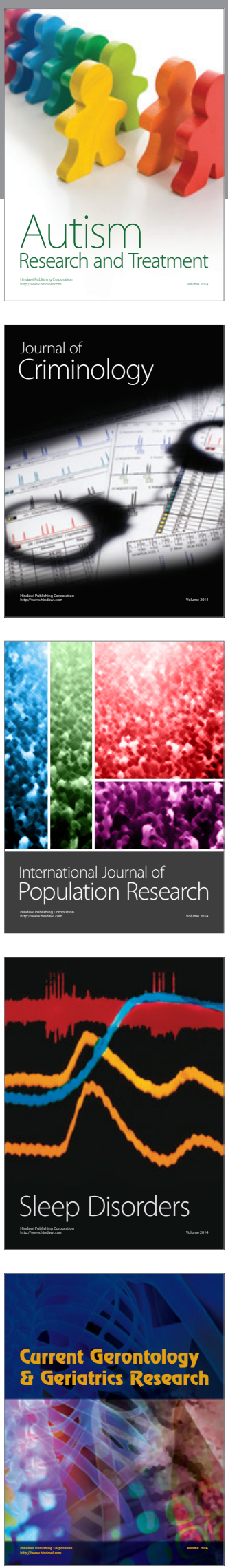
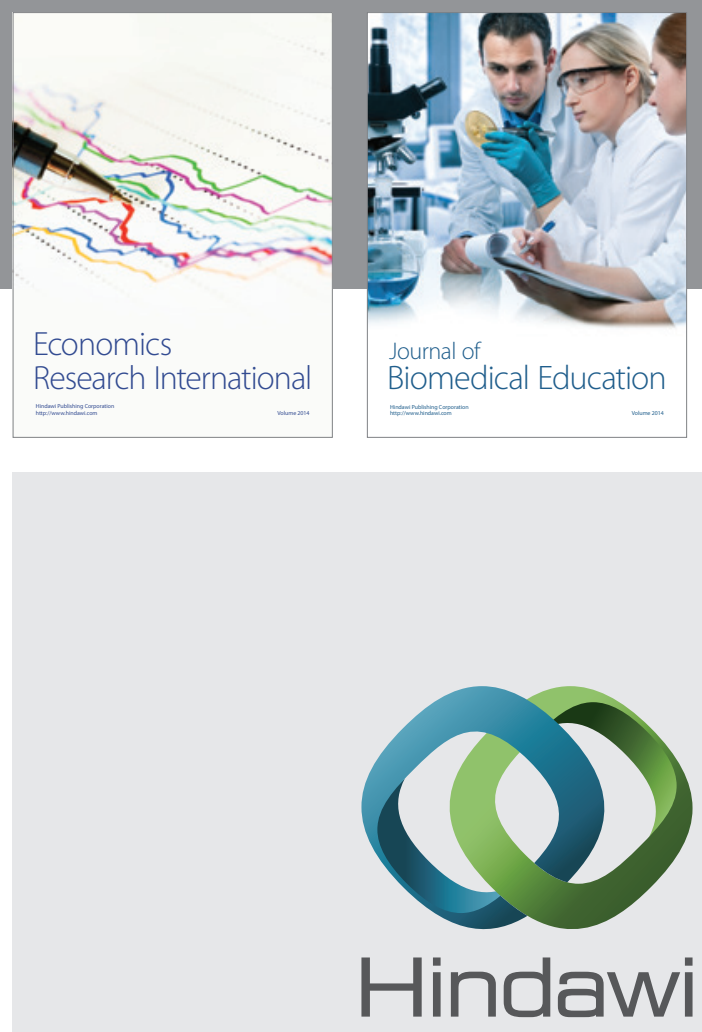

Submit your manuscripts at

http://www.hindawi.com
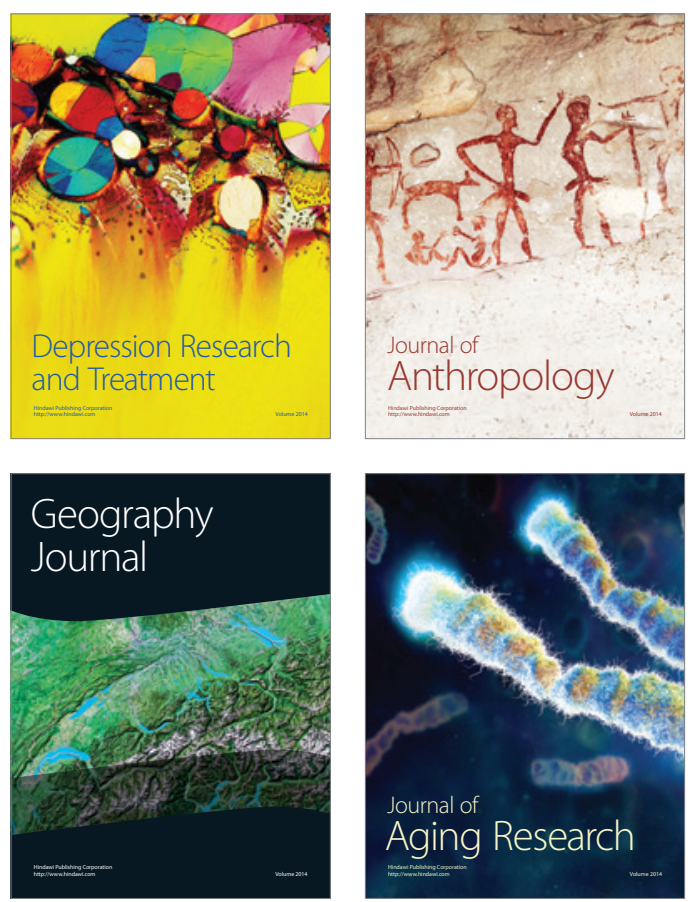
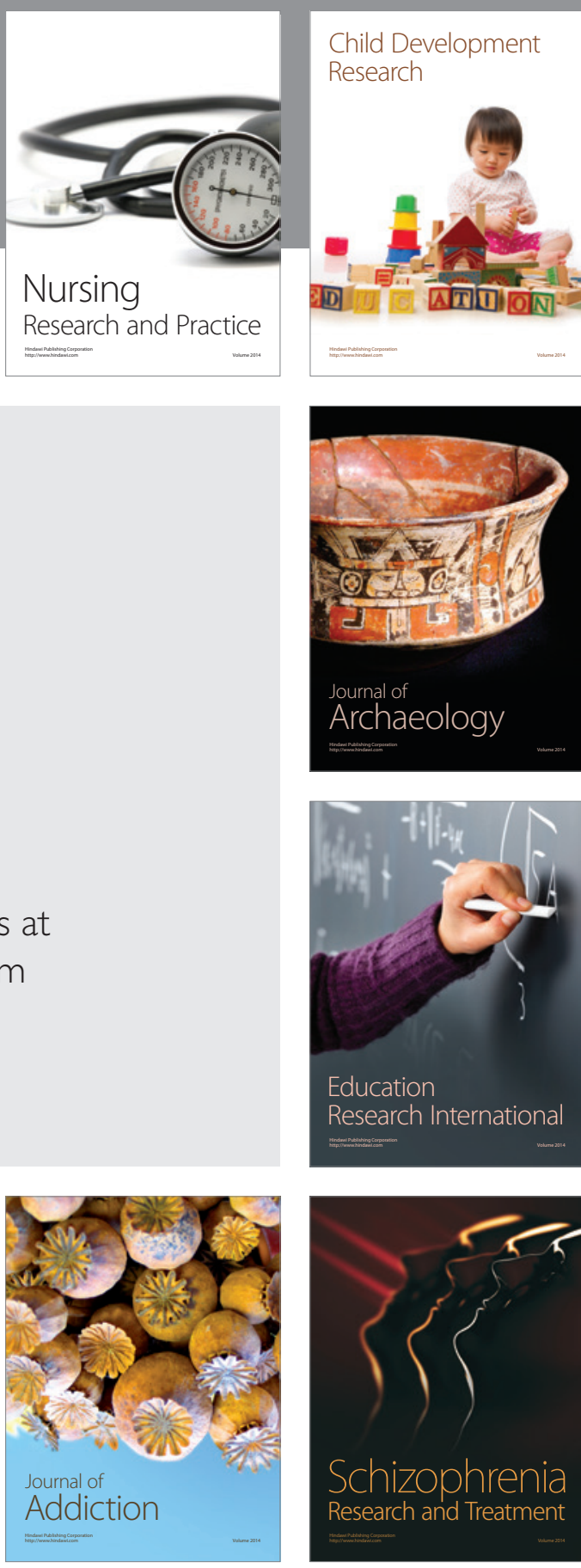

(D)
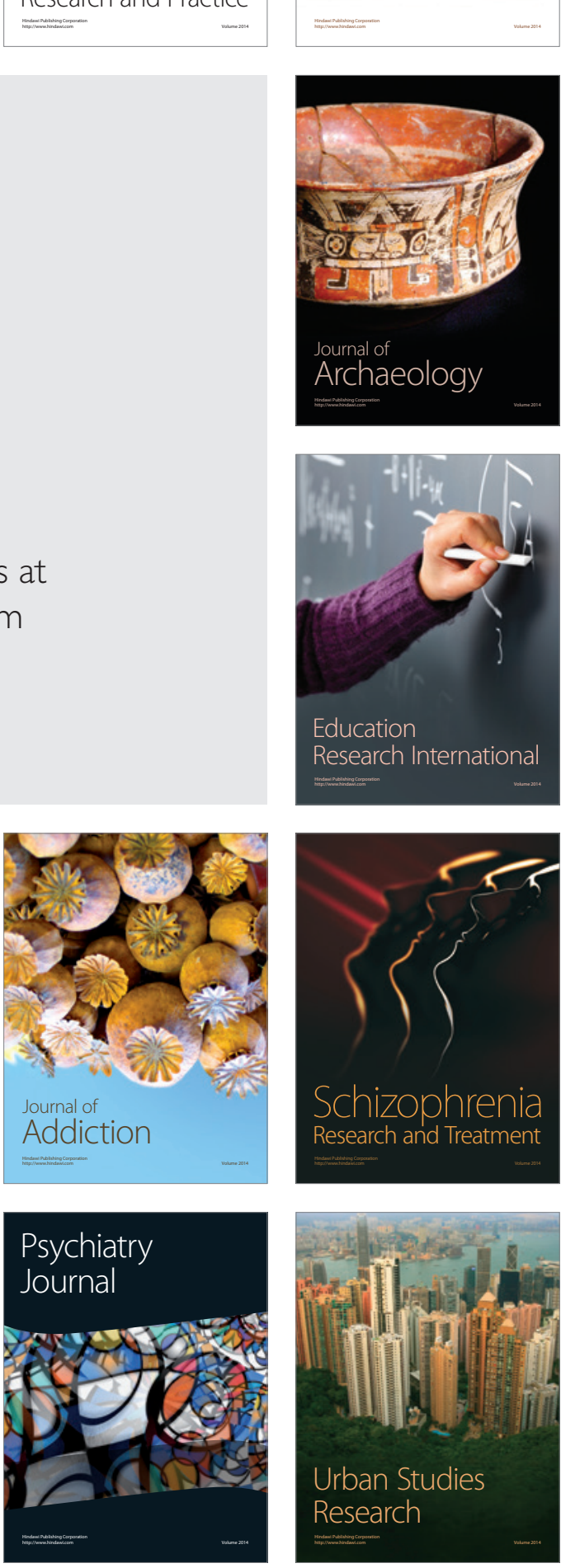